\title{
Using satellite-based rainfall data to support the implementation of environmental water requirements in South Africa
}

\author{
T Sawunyama* and DA Hughes \\ Institute for Water Research, Rhodes University, PO Box 94, Grahamstown 6140, South Africa
}

\begin{abstract}
The methods currently available in South Africa to implement environmental flows are based on real-time rainfall-runoff models (which require accurate inputs of rainfall data) or the use of flow gauges. Both methods are useful but have limitations which must be fully understood. The main limitation of the latter approach is that there are few gauges that measure natural flow conditions in the country, and installing a new gauge can only provide information on the variability of flow characteristics after a very long period. The main limitation of utilising real-time rainfall-runoff models is that many of the rainfall stations that provided data in the past have recently closed down, while it is difficult to obtain real-time data from those that remain. The use of satellite data offers an effective and economical substitute to rain-gauge data for calculating areal rainfall estimates in sparsely-gauged regions. This study presents some examples of the use of real-time rainfall-runoff models with simple correction procedures to raw satellite rainfall estimates, which are available in near real-time from National Oceanic and Atmospheric Administration's Climate Prediction Center (NOAA CPC). The correction factors were established using existing historical rain-gauge based spatial data, over the period during which they coincide with the satellite data. The corrected satellite rainfall data were used as inputs into a pre-calibrated Pitman monthly hydrologic model which simulates natural stream flows. The results from pilot case studies demonstrate the usefulness of satellite rainfall data in hydrological modelling which supports the implementation of environmental water requirements.
\end{abstract}

Keywords: rain-gauge, real-time rainfall-runoff modelling, environmental water requirements, satellite rainfall data

\section{Introduction}

Legislation pertaining to the management of environmental water requirements (EWR) has been in place in South Africa since 1998 (RSA, 1998) and a number of methods have been developed to support the determination of EWR, which are referred to locally as the ecological Reserve (O'Keeffe et al., 2002; Hughes and Hannart, 2003; King et al., 2003). Despite the different methods used to determine EWR, the outputs have been standardised (Hughes and Mallory, 2008) to consist of a set of flows for each calendar month and associated with different assurances, where assurance is the equivalent of the percentage time that any specific flow is expected to be equalled or exceeded. The assurance tables are therefore directly equivalent to flow duration curves that are frequently used to summarise time-series of hydrological data. The standard assurance tables consist of requirements for both low flows and high flows, where low flows are assumed to be the more or less continuous background flows that change relatively slowly, while the high flows consist of sets of events that are required to perform specific geomorphological (e.g. maintaining sediment transport) or ecological (e.g. fish spawning) functions.

The assurance tables only specify how frequently flows of a specific magnitude should be equalled or exceeded; they do not indicate when such flows should occur. The assumption in all of the methods is that the timing of different flow magnitudes should reflect the temporal variations in the

\footnotetext{
* To whom all correspondence should be addressed.

IIII +27(46) 622 401; fax: +27(46) 622 94274; e-mail: intosawuz@yahoo.com

Received 30 October 2009; accepted in revised form 31 May 2010.
}

natural flow regime, i.e. the high assurance drought flows should occur during naturally-occurring dry periods, while the lower assurance higher flows should only occur during wetter periods. This is consistent with the internationally accepted natural flow paradigm (Richter et al., 1997). The implication for the design of an implementation approach is that some information is required about natural stream-flow variations so that the appropriate flow volume can be selected from the assurance table on any specific day or month. Where a stream-flow gauging site exists that approximately measures natural flow conditions, the real-time observations can be used to determine the variations in EWR. Such an approach is currently being applied in the management of EWR releases from the Berg River Dam in the Western Cape Province (Abban et al., 2009). However, there are many situations where appropriate stream-flow gauges do not exist, or where the flow regime that they are monitoring is impacted by upstream water resource developments and is no longer a reflection of natural conditions.

Hughes and Mallory (2008) suggested an alternative approach for managing the low-flow component of EWR which is based on the use of a real-time hydrological model driven by daily rainfall inputs to simulate real-time natural flows. The motivation for the use of this approach was that the Pitman monthly model (Hughes et al., 2006) has been established for the whole country (Middleton and Bailey, 2008) at the scale of so-called quaternary catchments (mostly with areas between 50 and $1000 \mathrm{~km}^{2}$ ). The simulated flows generated by this model for the historical period 1920 to 2005 are frequently used for other water resource planning and management purposes. The main issue with the use of the model for real-time applications is therefore associated with the 
availability of real-time rainfall data that are consistent with the rainfall data used in the historical simulations. Hughes et al. (2008) provide a detailed description of the approach and an example application in the Thukela River basin in KwaZuluNatal Province. The method represents an attempt to integrate EWR and water-use operating rules in catchments that are controlled by reservoirs and associated releases, as well as in areas where water use is mainly through run-of-river abstractions. In the latter case, the operating rules mainly consist of water-use restrictions during drought periods to ensure that the EWR are satisfied.

The approach is a 'near real-time' updating of a monthly rainfall-runoff model based on a set of selected reporting rain gauges. The terminology 'near real-time' pertains to the fact that the method uses daily rainfall data as the primary input, but the hydrological model operates on a monthly time step. The daily rainfall data do not therefore have to be updated every day, and for the purposes of determining the low flow EWR an updating cycle of 7 to 10 days is perfectly adequate. The simulated natural monthly flows are used as the trigger signal to determine the EWR, the restriction rules to apply to run-of-river abstractions and the releases from reservoirs to meet user requirements. The approach is currently limited to managing the low-flow component of the flow regime, although Hughes et al. (2008) offer suggestions for managing high-flow EWR releases. The initial applications of the method relied on station rainfall data, but pilot studies in the Thukela basin and elsewhere revealed that there are problems with using rain-gauge data in real-time hydrological modelling in South Africa. The main problem lies in the decrease in the density of the rainfall monitoring network in South Africa in recent years, which is exacerbated by frequent periods of missing or unreliable data. A further problem lies in the long delays (in excess of 2 months) that are experienced in accessing the data for most stations. There are very few stations for which the data are immediately available from the South African Weather Services (SAWS). It is also worth noting that the daily report only includes stations for which rainfall was reported, while other stations could have experienced missing data problems or no rain.

On the basis of this experience it was clear that future applications of the method could not rely on the station rainfall data being available in real-time, and it was decided to investigate the use of global or regional satellite-based rainfall products. The Institute for Water Research (IWR) at Rhodes University has already had quite a lot of experience with using such data in hydrological modelling research and IWR researchers were therefore familiar with some of the issues and problems, in addition to having a clear understanding of which satellite-based rainfall products might be suitable for the purposes of this study (Hughes, 2006; Sawunyama and Hughes, 2008; Sawunyama, 2009). The focus of the present study is therefore on the use of operational satellite-based rainfall estimates available in realtime (with an approximate 2-day delay) from the National Oceanic and Atmospheric Administration's (NOAA) Climate Prediction Center (CPC), produced since January 1996 for the Famine Early Warning System (FEWS) project of the U.S. Agency for International Development (USAID). The use of satellite-based products is seen as a crucial step if hydrological approaches that support the implementation of EWR in real-time are to be successful. The study presents the results of 4 pilot-case studies, in the catchments of the Letaba, Luvuvhu, Kat and Komati rivers of South Africa.

\section{Data and methods}

\section{Satellite-based rainfall estimates}

From 1998 to 2000, the NOAA/CPC produced Version 1.0 of the satellite-based rainfall estimates using the algorithms of Herman et al. (1997), while Version 2.0 has been in production since January 2001 (Xie and Arkin, 1997; Love et al., 2004). The basic inputs for the creation of the satellite-based rainfall estimates are geostationary thermal infrared (IR) satellite imagery, passive microwave (PM) imagery, and daily raingauge reports from the Global Telecommunications Systems (GTS) of the World Meteorological Organisation (WMO). For Version 1.0, rainfall was estimated from cold-cloud duration (CCD) calculated with a temperature threshold of $235 \mathrm{~K}$ from the IR imagery, ingested on a 30 -minute basis and aggregated on a daily time-step, with bias removed from IR-based estimates using interpolated GTS rainfall fields (Herman et al., 1997). The Version 2.0 estimates incorporate additional satellite data from the Special Sensor Microwave/Imager (SSM/I) satellite precipitation estimates acquired at a frequency of up to 4 times a day and the Advanced Microwave Sounding Unit $\mathrm{B}$ (AMSU-B) satellite rainfall estimates acquired twice a day (Love et al., 2004). In Version 2.0, rainfall is first estimated separately from 3 satellite sources with a maximum likelihood approach that uses weighting coefficients inversely proportional to the square of individual data random errors. Finally, the satellite rainfall estimates are merged with interpolated rainfall from available GTS data (approximately 1000 usable stations in Africa) so that the satellite data provide the field shape and are anchored by the GTS data (Love et al., 2004). The final daily satellite-based rainfall estimates known as CPC/FEWS used in this study are available at 0.1 of a degree spatial resolution and can be downloaded freely from the FTP site ftp://ftp.cpc.ncep.noaa.gov/fews/newalgo est). The spatial extent of the data covers the whole of the Africa region from $40^{\circ} \mathrm{S}$ to $40^{\circ} \mathrm{N}$ and $20^{\circ} \mathrm{W}$ to $55^{\circ} \mathrm{E}$. The data are also available for central and southern Asia.

\section{WR2005 data}

While it is accepted that the parameters used within a hydrological model for a specific catchment are not independent of the hydro-meteorological data used to force the model, it is also recognised that the satellite data are too short to be used for model calibration. They do not cover the variability of wet and dry periods expected under South African hydrological conditions. The parameter sets used for the model were therefore based on the information provided in the WR2005 study and these parameter values were obtained through calibration and regionalisation using the hydro-meteorological data sets given in WR2005 (Middleton and Bailey, 2008) for the period October 1920 to September 2005. The catchment average rainfall data were generated using spatial interpolation of selected station data, where the selection was based on the assumed reliability and representativeness of the station rainfall data (Middleton and Bailey, 2008).

\section{Processing the satellite data}

The methodology followed in this study was the extraction of the original satellite rainfall files from the NOAA website followed by the derivation of catchment average-rainfall time series. The initial catchment rainfalls were estimated using 
Figure 1

Letaba river catchment with grid overlays of 0.10 spatial resolution matching the CPC/FEWS daily satellite rainfall grid (polygons represent quaternary catchments)

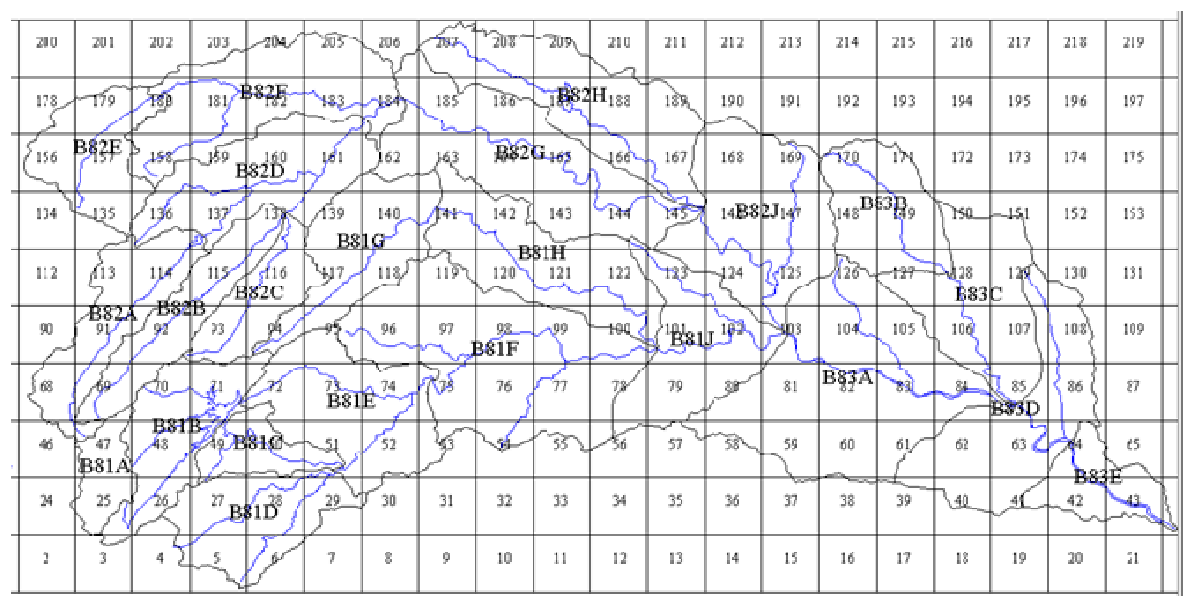

area-weighted sums of the gridded satellite data where the weights were determined by overlaying $0.1^{\circ}$ grids (matching the satellite data grids) over the quaternary catchment boundaries as shown in Fig. 1 for the Letaba River example, using the SPATSIM (Spatial and Time Series Information Modelling) software package (Hughes and Forsyth, 2006). Arc Map Version 9.3 was used to estimate the proportion of the catchment area covered by the grids in cases where only part of the grid falls within a quaternary catchment boundary (e.g. Grid 25 and 47 of B81A in Fig. 1).

Sawunyama and Hughes (2008) have already demonstrated that the original satellite estimates need to be corrected, especially in areas where rainfall spatial variability is high due to orographic influences. In this study, the satellite data were corrected using the gauge-based WR2005 spatially-averaged rainfall data over the period where the 2 datasets coincide (i.e. 2001 to 2005). This period was split into 2 periods with $10 / 2001$ to $09 / 2003$ used to establish the correction factors and the period $10 / 2003$ to $09 / 2005$ used to validate the correction procedure. The correction was based on the non-linear rainfall frequency curve correction procedure of Sawunyama and Hughes (2008). This procedure was developed to adjust the frequency characteristics of the original satellite rainfall and is ideally applied using overlapping record lengths that represent the full range of rainfall depths. Unfortunately, the datasets available in this study coincide for a relatively short period of 4 years in some catchments (e.g. Luvhuvhu) and 5 years in others (e.g. Letaba, Komati and Kat).

The correction procedure involves transferring source rainfall (satellite) values to destination values (i.e. the corrected time series) through the use of similar percentage points (probabilities) from the respective rainfall frequency of exceedance curves (RFCs), which are a summary of the relationship between rainfall magnitude and frequency, and therefore the variability within a time series (Sawunyama, 2009). The source rainfall record is the original monthly satellite data, while the destination RFC is based on WR2005 rainfall data for the period during which the datasets coincide. The assumption is that the destination RFC (gauge-based data) is representative of the frequency characteristics of 'real' catchment rainfall given that in situ rain gauge estimates are widely used as 'ground truth' for radar and satellite rainfall measurements (Seed and Austin, 1990). The procedure involves generating tables of monthly rainfall values for each month for 17 fixed percentage points of the RFCs $(0.01,0.1$, $1,5,10,20,30,40,60,70,80,90,95,99,99.9$ and $99.99 \%$; see Hughes and Smakhtin, 1996 for more details). The tables are used to identify the percentage points corresponding to each rainfall value in the time series with log-interpolation being used to define the position between the fixed percentage points. An estimate of the rainfall in any month at the destination point (corrected rainfall record) is made by identifying the percentage point position on the source RFC for the monthly rainfall in the source record and reading off the rainfall value for the same percentage point from the destination RFC as shown in Fig. 2. Figure 3 shows an example comparison of 3 rainfall frequency curves to demonstrate the effect of the transformation process. 


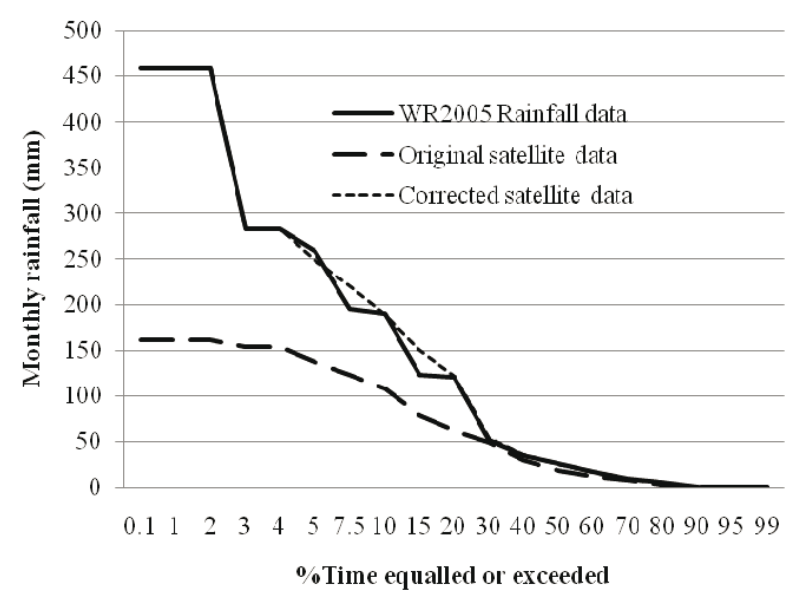

Figure 3

Comparison of RFC curves of 3 rainfall datasets (WR2005, satellite original and satellite

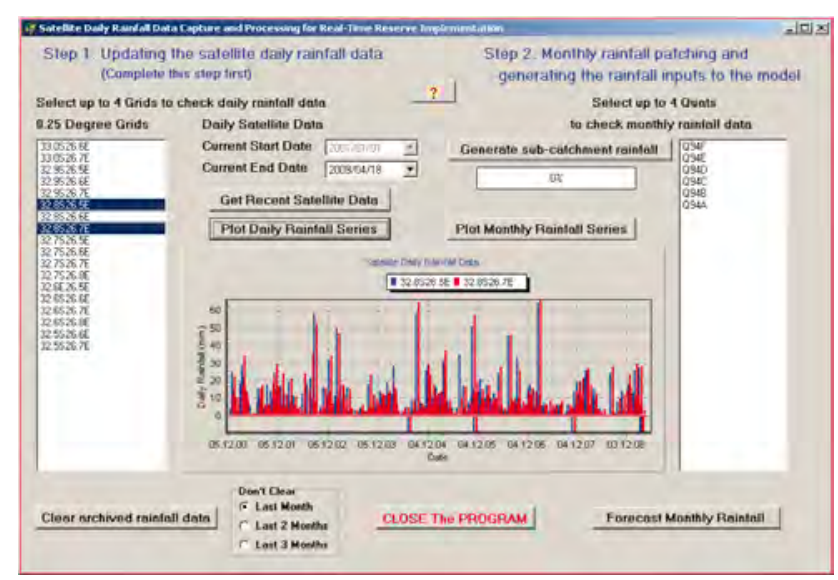

Figure 4

Main screen of the satellite rainfall capture process, illustrating the software user interface

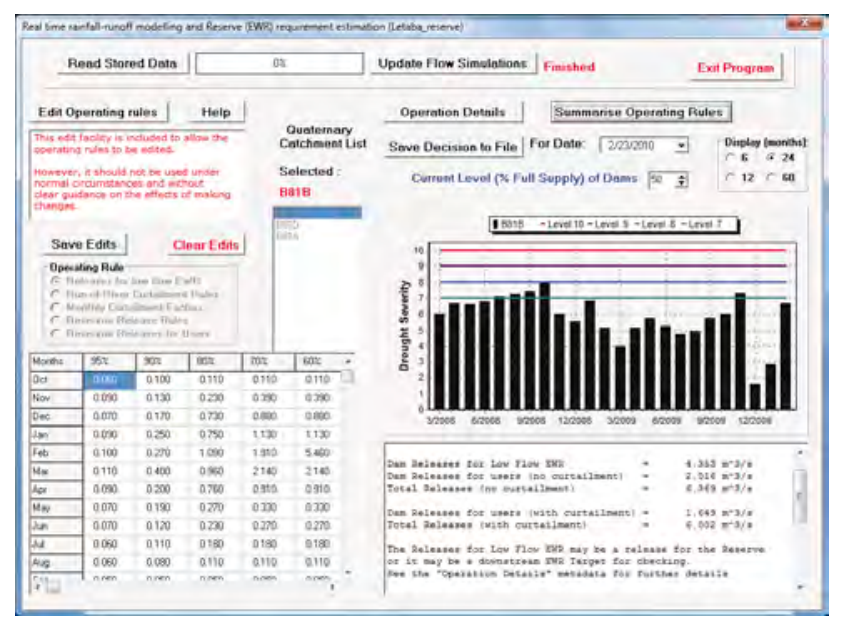

Figure 5

Main screen of the real-time Reserve management model illustrating software interface (Letaba example)

\section{Rainfall data capturing process}

As part of this study, software (Fig. 4) was developed for capturing the rainfall data that allowed quick and efficient access to the satellite data and that included all of the following procedures:

- Downloading the raw satellite data from the NOAA website

- Extracting the gridded satellite data for the relevant area

- Converting the gridded satellite data into catchment (using quaternary catchment boundary) daily rainfall estimates based on the area-weighting procedure discussed above and accumulating them to monthly rainfall totals

- Correcting the monthly satellite data frequency characteristics using pre-determined correction factors (based on a comparative analysis of the satellite and WR2005 data, as described above)

- Forecasting the daily data to the end of the current month using a simple process based on the identification of similar patterns of rainfall in the historical record. The purpose of this process is to be able to generate monthly rainfall totals before all of the daily inputs are available for the current month.

- Inclusion of graphical display facilities to allow checking for any gross errors in the satellite data or correction process (this includes displaying the original daily data as well as the monthly catchment estimates)

The processed satellite data are added to the existing WR2005 monthly records for the period October 1950 to September 2000 (i.e. prior to the availability of the satellite data). This is to ensure that the simulated flows generated in the real-time management software have a reasonably long record length to use for estimating the exceedance frequency values of the current month's natural flows. The satellite data on their own are not long enough (currently about 9 years) for this purpose.

\section{Updating natural simulated monthly streamflows}

The SPATSIM version of the Pitman monthly rainfall-runoff model is used to update the quaternary natural simulated flow estimates which are used in the real-time EWR management model (Fig. 5). The full details of the Pitman model (Hughes, 2004; Hughes et al., 2006) and its implementation in the real-time management software (Hughes and Mallory, 2008) are beyond the scope of this paper. The inputs consist of the updated monthly catchment average rainfall data (generated by the satellite data capture program), the pre-determined parameters of the Pitman model and the operating rules for the various quaternary catchments in the system (Hughes and Mallory, 2008). As illustrated in Fig. 5, the updated flow simulations can be used to summarise the operating rule decisions for the past 6, 12, 24 or 60 months (graph, Fig. 5). These decisions are based on interpreting the simulated monthly flows through the monthly flow duration curves to determine a drought severity index. Essentially a high drought severity corresponds to a flow that has a high exceedence frequency, while a low drought severity is equated to higher flows with lower exceedence frequencies. The drought severity index is then used to determine the EWR requirements and water-user restriction levels according to the input operating rules. These operating rules are pre-determined after detailed analyses of the system operation using a water resource system yield model (Mallory, 2005). 


\section{Results}

A comparison of frequency curves of original satellite estimates with rain-gauge based estimates showed that the original satellite data substantially underestimate rainfall totals and this only improves after employing correction factors (refer to Fig. 3). Both the original and corrected satellite results (for Letaba and Komati in Fig. 6) have showed that there is a strong correlation $\left(R^{2}>80 \%\right)$ between satellitebased and rain gauge-based estimates. However, there are exceptional cases (e.g. Kat River, Fig. 6), where a low correlation coefficient of 0.52 exists between the original satellite and raingauge data. However, after correction of rainfall frequencies the correlation coefficient improved to 0.70 . The Kat example illustrates a source of uncertainty in rainfall estimates and requires more attention (Sawunyama, 2009).

Table 1 shows the results of hydrological modelling when the WR2005 flows are compared with satellite-based flows for the calibration period. Table 2 shows the validation results of using the corrected satellite rainfall data. The focus of the results is on the low-flow rather than high-flow component of the hydrograph, and therefore log-transformed statistics are used in the tables. Given that the Reserve management programme (Hughes et al., 2008) does not use absolute values but frequency characteristics of the simulated flow, further evaluation of the results (i.e. for the period for which the satellite data coincide with historical gauge data) was based on frequency duration curves. Figure 7 displays streamflow time series plots
Letaba (B81J)

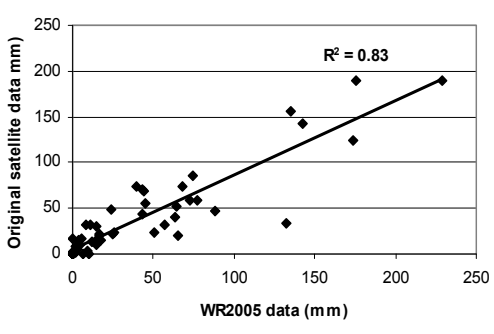

omati (X11J)

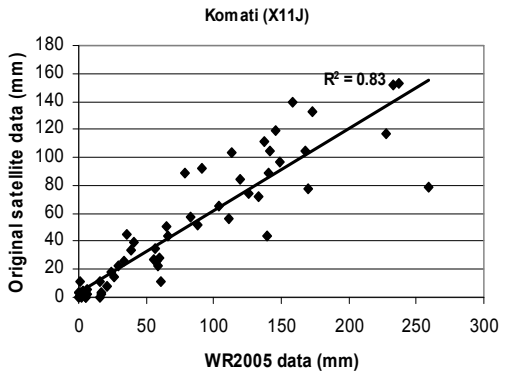

Kat (Q94A)

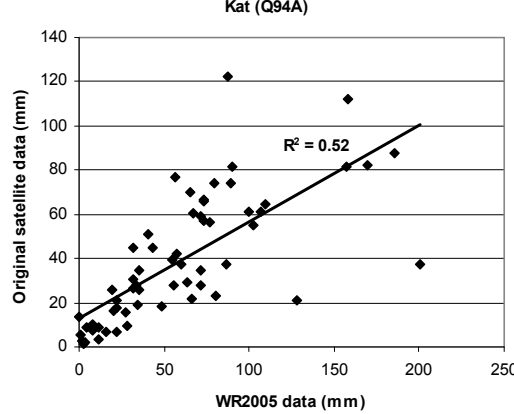

Letaba (B81J)

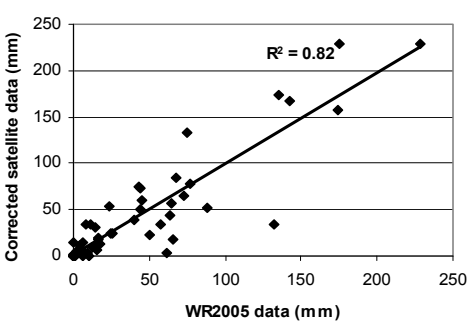

Komati (X11J)

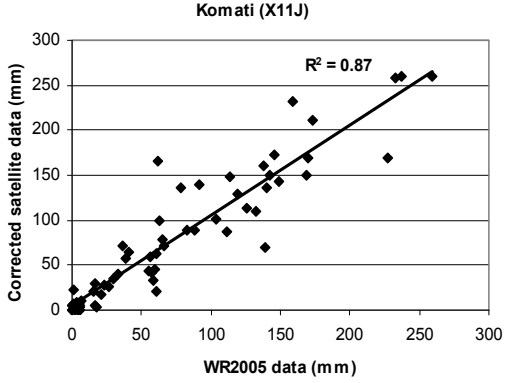

Kat (Q94A)

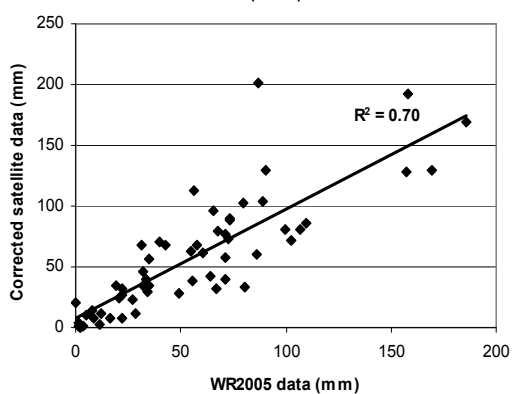

igure 6

Graphs of correlations between WR2005 and original (left) and corrected (right) satellite rainfall data for the 3 pilot river catchments (Letaba, Komati and Kat
Figure 7

Time series streamflow (left) and FDC (right) comparisons for the WR2005 data and real-time satellite based data (Luvhuvhu, A91H
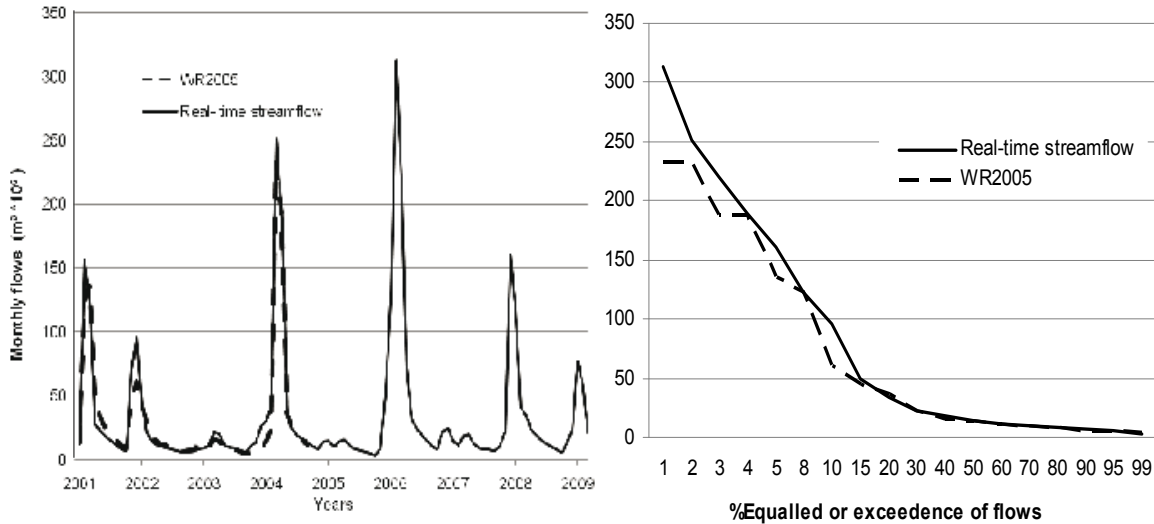

Table 1

Model simulation results of satellite-based data (with reference to WR2005 flows where datasets coincide: rainfall correction period $10 / 2001$ to 09/2003) for the selected sub-catchments in 4 pilot catchments

\begin{tabular}{|l|c|c|c|c|c|}
\hline \multirow{2}{*}{$\begin{array}{l}\text { Catchment } \\
\text { name }\end{array}$} & \multirow{2}{*}{ Subcatchment } & \multicolumn{2}{|c|}{ Un transformed flows (Q) } & \multicolumn{2}{|c|}{ Log-transformed flows $\{$ In(Q)\} } \\
\cline { 3 - 6 } & & \%Diff Mn & CE & \%Diff Mn & CE \\
\hline Luvhuvhu & A91H & -3.78 & 0.84 & -6.96 & 0.85 \\
\hline Komati & X11J & 15.11 & 0.75 & 14.13 & 0.86 \\
\hline Kat & Q94A & 20.87 & 0.37 & -32.38 & 0.83 \\
\hline Letaba & B81J & -12.83 & 0.91 & -2.45 & 0.96 \\
\hline
\end{tabular}

Notes: \%Diff Mn is percentage difference in mean monthly flows and CE is the Nash Coefficient of Efficiency for both un-transformed (high) flows $(Q)$ and log-transformed (low) flows $\{$ In $(Q)\}$. For Luvhuvhu catchment the correction period is 10/2001 to09/2002. 

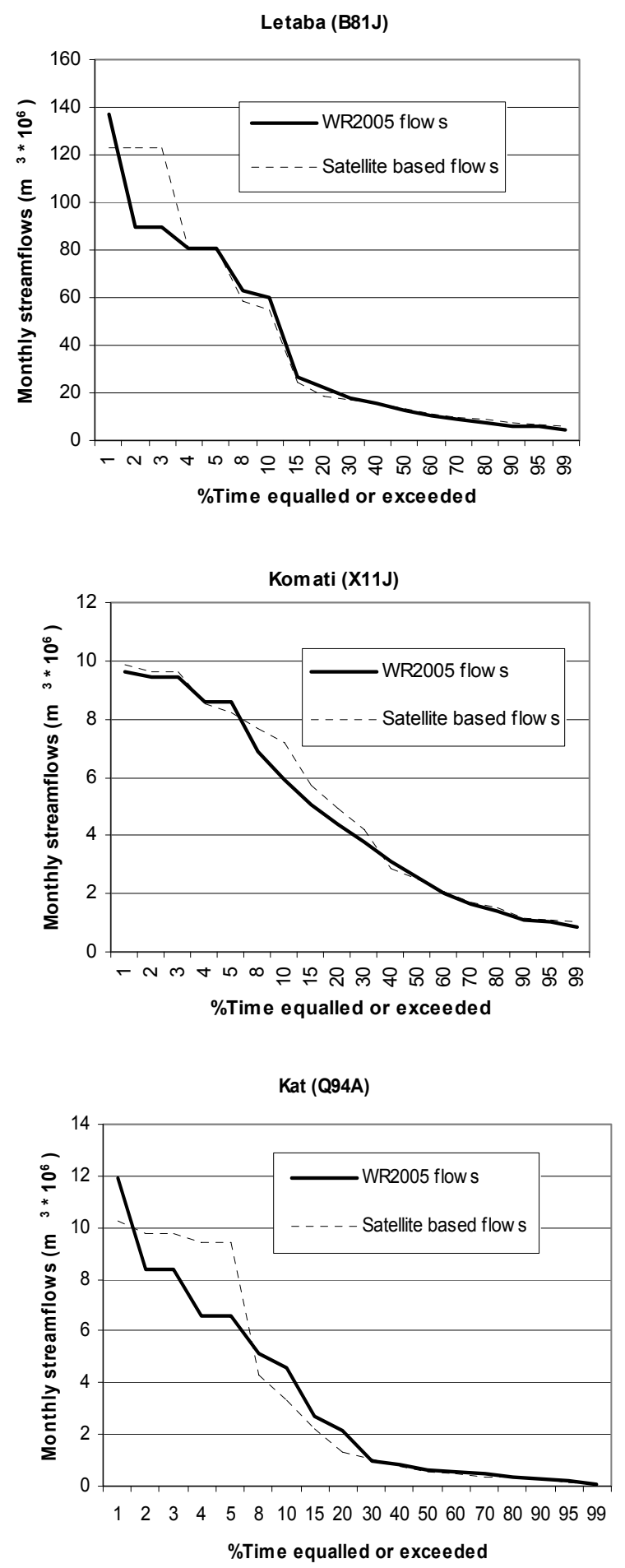

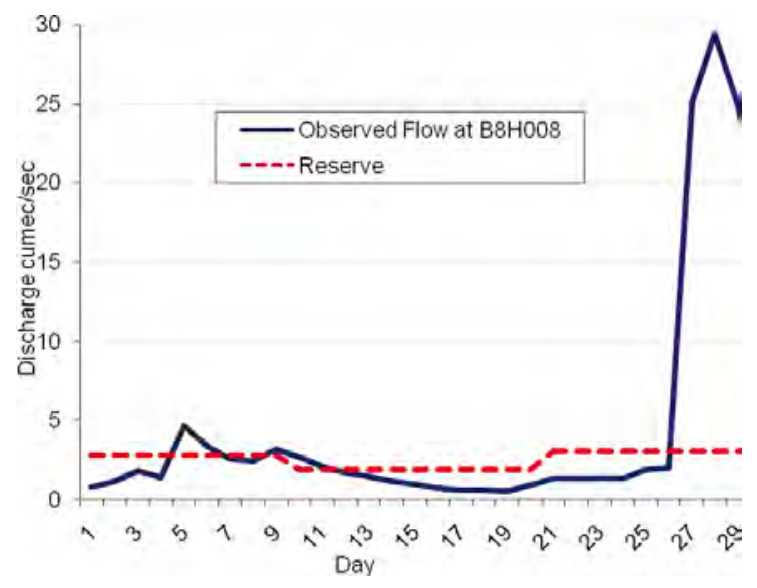

Figure 8 (left)

Frequency duration curves comparison of WR2005 and satellite-based flow data for 3 river catchments

Figure 9 (above)

Illustration of Reserve monitoring at a 10-day interval at Letaba Ranch

and flow duration curves (FDC) for the WR2005 data (01/2001 to $09 / 2004$ ) and the simulations based on the satellite data (from 01/2001 to 03/2009) for the Luvhuvhu catchment (i.e. quatenary catchment A91H). Figure 8 shows flow duration curves for the other 3 pilot catchments namely Komati, Kat and Letaba rivers. Of relevance from these flow duration curves are flows that are equalled or exceeded within the range of $10 \%$ to $95 \%$ of the time. This is the range which is being used in the Reserve determination (Hughes et al., 2008). Clearly, from the flow duration curves in Fig. 8, the low flows are more correctly simulated than high flows. This finding is consistent with statistics in Tables 1 and 2 as well as results from previous studies (Sawunyama and Hughes, 2008; Sawunyama, 2009). Sawunyama and Hughes (2008) have already demonstrated examples which show that the observed flows, WR2005 flows and satellite-based flows are very similar in catchments with low development impacts and satellite-based flows are therefore appropriate to support the implementation of ecological water requirements in South Africa.

The applicability of the approach was demonstrated by monitoring the ecological water requirement at stream flow gauge (B8H008, located at Letaba Ranch (outlet of B81J, Fig. 1) in the Letaba catchment. The method is used to manage releases at Tzaneen Dam so as to meet downstream water abstractions and the ecological water requirement at site EWR 4, which is also at the outlet of the B81J quaternary catchment (Fig. 1). An estimate of minimum flows at EWR4 is relevant as

Table 2

Model simulation results of satellite-based data (with reference to WR2005 flows where datasets coincide: rainfall validation period 10/2003 to 09/2005) for the selected sub-catchments in 4 pilot catchments

\begin{tabular}{|l|c|c|c|c|c|}
\hline \multirow{2}{*}{$\begin{array}{l}\text { Catchment } \\
\text { name }\end{array}$} & \multirow{2}{*}{ Subcatchment } & \multicolumn{2}{|c|}{ Untransformed flows (Q) } & \multicolumn{2}{c|}{ Log-transformed flows $\{$ In(Q)\} } \\
\cline { 3 - 6 } & & \%Diff $\mathbf{M n}$ & CE & \%Diff Mn & CE \\
\hline Luvhuvhu & A91H & 15.88 & 0.98 & 10.78 & 0.78 \\
\hline Komati & X11J & 1.77 & 0.47 & 2.82 & 0.83 \\
\hline Kat & Q94A & 25.21 & -0.21 & -4.82 & 0.35 \\
\hline Letaba & B81J & 66.40 & -2.74 & 10.32 & 0.70 \\
\hline
\end{tabular}

Notes: For Luvhuvhu catchment the validation period is 10/2003 to 09/2004 
this has a major impact on flows required for meeting ecological requirements within the Kruger National Park. Monitoring compliance was assessed by checking the flows passing flow gauge B8H008. The Reserve management programme (Fig. 5) illustrates operational decision outputs for Tzaneen Dam and shows the amount of releases required for meeting the low EWR flow and the needs of downstream users on any decision date. Figure 9, however, illustrates the estimate of the EWR derived through the use of the drought index (Fig. 5) to identify the percentage of time that the natural flows are equalled or exceeded, from which the EWR is then interpolated. The model is updated at 10-day intervals in each month. Clearly there are certain days of the month (more than 60\%) when the Reserve is not met, and this information is very critical and should be communicated to the dam operator to enable them to act decisively. The methodology thus appears to be adequate for use in the implementation of environmental water requirements in South Africa.

\section{Observations and conclusions}

The correction procedures used in this study have been tested by comparing the use of the satellite-based monthly rainfalls with the use of WR2005 monthly rainfall data as inputs to the monthly Pitman rainfall-runoff model used for the realtime flow estimates. The uncertainties associated with using satellite-based data have already been discussed (Sawunyama and Hughes, 2008; Sawunyama, 2009). While the satellite rainfall-capturing process is automated and easy to use there remain some doubts about the degree to which the satellite data can be considered to be representative of real rainfall patterns, especially in areas with high spatial variability of rainfall such as the Kat River catchment (Sawunyama, 2009). There is a high degree of variability in the results obtained in the 4 pilot catchments studied, which is an indication that satellite rainfall data may be more applicable in some parts of the country than in others (Fig. 6).

In general terms, the satellite data appear to be adequate for real-time implementation of environmental water requirements. It should be recognized that the real-time simulated flow data are not directly used in the low-flow management procedure. The basis of the Reserve management programme (Hughes et al., 2008) is to use the frequency characteristics of the simulated flow data through flow-duration curves (Fig. 8). Accurate representation of the absolute values of the simulated flow is therefore less important than getting the sequences of dry and wet periods correctly simulated. This takes some pressure off any requirement for accurate rainfall data. However, it is still important that spatial variations in rainfall over the entire management area of the catchment are accurately represented. Finally, given the apparently poor status of ground-based rainfall data collection and dissemination in South Africa at present, satellite-derived data appear to represent the only alternative.

\section{Acknowledgments}

The authors would like to express their gratitude to the Water Research Commission (WRC), the Department of Water Affairs (DWA) and the International Foundation Science (IFS) who co-funded the study. We also wish to thank the NOAA team for providing satellite archived data used in the study and David Forsyth of the Institute for Water Research for his technical support.

\section{References}

ABBAN B, SHAND MJ, KAMISH W, MAKHABANE M, VAN ZYL $B$ and TENTE T (2009) Decision support system for the Berg River Dam and supplement scheme. Paper presented at the International Conference on Implementing Environmental Water Allocations. Port Elizabeth, South Africa, Feb. 2009.

HERMAN A, KUMAR V, ARKIN P and KOUSKY J (1997) Objectively determined 10-day African rainfall estimates created for famine early warning systems. Int. J. Remote Sens. 18 (10) 2147-2159.

HUGHES DA (2004) Incorporating ground water recharge and discharge functions into an existing monthly rainfall-runoff model. Hydrol. Sci. J. 49 (2) 297-311.

HUGHES DA, ANDERSSON L, WILK J and SAVENIJE HHG (2006) Regional calibration of the Pitman model for the Okavango River. J. Hydrol. 331 (1-2) 30-42.

HUGHES DA and FORSYTH DA (2006) A generic database and spatial interface for the application of hydrological and water resource models. Comp. Geosci. 32 1389-1402.

HUGHES DA and HANNART P (2003) A desktop model used to provide an initial estimate of the ecological instream flow requirements of rivers in South Africa. J. Hydrol. 270 (3-4) 167-181.

HUGHES DA and MALLORY SJL (2008) Including environmental flow requirements as part of real-time water resource management. River Res. Appl. 24 (6) 852-861.

HUGHES DA, MALLORY SJL and LOUW D (2008) Methods and Software for the Real-Time Implementation of the Ecological Reserve - Explanations and User Manual. WRC Report No. 1582/1/08. Water Research Commission, Pretoria, South Africa.

HUGHES DA and SMAKHTIN VY (1996) Daily flow time series patching or extension: a spatial interpolation approach based on flow duration curves. Hydrol. Sci. J. 41 (6) 851-871.

KING J, BROWN C and SABET H (2003) A scenario-based holistic approach to environmental flow assessments for rivers. River Res. Appl. 19 619-639.

LOVE TB, KUMAR V, XIE P and THIAW W (2004) A 20 year Daily Africa Precipitation Climatology using satellite and gauge data. Proc. $14^{\text {th }}$ Conf. Appl. Climatol., Am. Meteorol. Soc. 11-15 January 2004, Seattle, WA.

MALLORY SJL (2005) The modelling of water restrictions applied in complex bulk water supply systems and the application of these techniques to operationalising the ecological Reserve. Paper presented at the $12^{\text {th }}$ South African National Hydrology Symposium, Midrand, South Africa, Sept. 2005.

MIDDLETON BJ and BAILEY AK (2008) Water Resources of South Africa, 2005 Study (WR2005). WRC Report No. TT 381/08. Water Research Commission, Pretoria, South Africa.

O'KEEFFE J, HUGHES DA and THARME R (2002) Linking ecological responses to altered flows, for use in environmental flow assessments: the Flow Stressor-Response method. Verh. Internat. Verein. Limnol. 28 84-92.

RSA (REPUBLIC OF SOUTH AFRICA) (1998) National Water Act. Act No. 36 of 1998. Pretoria, South Africa.

RICHTER DD, BAUMGARTNER JV, WIGINTON R and BRAUN DP (1997) How much water does a river need? Freshwater Biol. 37 231-249.

SAWUNYAMA T (2009) Evaluating Uncertainty in Water Resources Estimation in Southern Africa: A Case Study of South Africa. Ph.D. Thesis, Institute for Water Research, Rhodes University.

SAWUNYAMA T and HUGHES DA (2008) Application of satellitederived rainfall estimates to extend water resource simulation modelling in South Africa. Water SA 34 (1) 1-9.

SEED AW and AUSTIN GL (1990) Sampling errors for raingaugederived mean areal daily and monthly rainfall. J. Hydrol. 118 (1-4) 163-173.

XIE P and ARKIN AP (1997) Global precipitation: a 17-year monthly analysis based on gauge observations, satellite estimates, and numerical model outputs. Bull. Am. Meteorol. Soc. 78 (11) 2539-2558. 
Available on website http://www.wrc.org.za

ISSN 0378-4738 (Print) = Water SA Vol. 36 No. 4 July 2010 ISSN 1816-7950 (On-line) = Water SA Vol. 36 No. 4 July 2010 